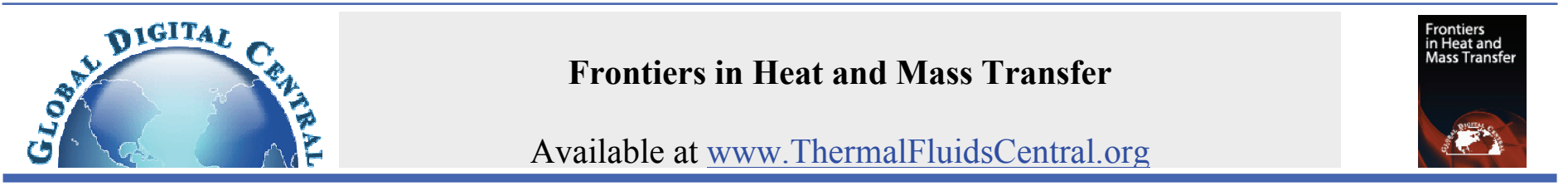

\title{
NUMERICAL STUDY OF AIR FORCED CONVECTION IN A CHANNEL PROVIDED WITH INCLINED RIBS
}

\author{
Oronzio Manca*, Sergio Nardini, Daniele Ricci \\ Dipartimento di Ingegneria Aerospaziale e Meccanica, Seconda Università degli Studi di Napoli \\ Real Casa dell'Annunziata, via Roma 29, 81031 Aversa, Italy
}

\begin{abstract}
Convective heat transfer may be enhanced passively by adopting rough surfaces. Ribs break the laminar sub-layer and create local turbulence in the channel, reducing thermal resistance and enhancing the heat transfer. However, higher losses are expected. In this paper a numerical investigation is carried out on air forced convection in a rectangular ribbed channel. A three-dimensional model is developed to study the effect of the angle between the fluid flow direction and the ribbed surface, provided with rectangular turbulators, in the turbulent flow. Simulations s that Nusselt numbers as well as the pressure drops increase as the inclination angles increase.
\end{abstract}

Keywords: Heat Transfer Enhancement, Turbulent Flow, Ribs, Forced Convection.

\section{INTRODUCTION}

Heat transfer enhancement is an active and important field of engineering research since it increases the effectiveness of heat exchangers. Suitable heat transfer augmentation techniques may achieve considerable technical advantages and savings of costs. There are various kinds of available techniques, adopted in many applications as heat exchangers for refrigeration, automotives, process industry, solar heater etc. According to Bergles et al. $(1985,1998)$ there are several enhancement techniques available. They identified thirteen different techniques, which can be segregated into two groupings: 'passive' and 'active' techniques. Passive techniques employ special surface geometries, like coated surfaces, rough surfaces, extended surfaces or swirl flow devices, fluid additives for enhancement. The active techniques require external power sources, such as mechanical aids, electric or acoustic fields and surface vibration, as pointed out by Webb et al. (2005).

Artificial roughness up to laminar sub-layer to enhance heat transfer coefficient is used in various application like gas turbine, blade cooling channels, heat exchangers, nuclear reactors and solar air heaters (Muluwork et al., 2000; Karwa et al., 2001) The use of artificial roughness in the form of repeated ribs has been found to be as an efficient method of enhancing the heat transfer to fluid flowing in the duct by several investigators (Giupta, 1993; Karwa et al., 1999; Liou and Hwang, 1993). The ribs break the laminar sub-layer and create local wall turbulence due to flow separation and reattachment between consecutive ribs, which reduce thermal resistance and greatly augment the heat transfer. The enhancement of heat transfer by flow separation and reattachment, caused by ribs, is significantly higher than compared to the fin-effect, linked to the increased heat transfer area (Lee and Abdel Moneim, 2001). However, the use of artificial roughness results in higher friction losses leading to excessive power requirement for the air flow through the duct. Therefore, it is desirable that the turbulence must be created only in the region very close to the heat transfer surface i.e. in the viscous sub-layer where the heat transfer takes place and the core flow should not be disturbed so as to avoid excessive friction losses. This can be achieved by keeping small the height of roughness elements in comparison with the duct dimensions.

Webb et al. (1971) developed heat transfer and friction factor correlations for turbulence air flow in tubes having rectangular repeated rib roughness. For developing and fully developed turbulent flow, heat transfer and friction characteristics of ducts with rib turbulators on two opposite wall of the square and rectangular ducts have been extensively studied, from experimental point of view. The literature on the computational side is also quite extensive. Lee et al. (1993), Iaccarino et al. (2002) and Tafti (2005) have carried out calculation to examine effects of ribs. The heat transfer measurement results for two different rib spacings, $p / e=14$ and 8 , indicate the importance of roughness geometry (Slanciasukas, 2001). Liou et al. (1993) performed both the numerical analysis and experimental study to investigate the heat transfer and the fluid flow behaviour in a rectangular channel flow with stream wise periodic ribs mounted on one of the principal walls. They have concluded that the flow acceleration and turbulence intensity are two major factors influencing the heat transfer coefficient. Experimental investigations have shown that the enhancement in heat transfer coefficients for air flow in a channel roughened with angled ribs is on the average higher than that roughened with 90 deg ribs of the same geometry. Secondary flows generated by the angled ribs are believed to be responsible for these higher heat transfer coefficients (Taslim et al., 1996). Ryu et al. (2007) studied both the thermal and fluid-dynamic behaviours of turbulent flows with two-dimensional ribs and three-dimensional blocks in the context of surface roughness effects. They solved the Reynolds-averaged Navier-Stokes equations, coupled with the k- $\omega$ turbulence model with near-wall treatment, by a finite-volume method. They analyzed different three dimensional configurations with ribs both in line and staggered. For the in-line cases they found that Nusselt number was about $20 \%$ lower than the results obtained for the 2-D simulations. Kiml et al. (2001) studied the effects of ribs arrangements on heat transfer and flow in rectangular channel as

\footnotetext{
*Corresponding author.Email: oronzio.manca@unina2.it
} 
application for gas turbine blade cooling. They found that he highest average heat transfer enhancement was achieved for the $60 \mathrm{deg}$ rib pattern, due to the strong rotational momentum of the secondary flow also comparing with the three rib patterns. Cho et al. (2000) compared the performances of discrete and continuous ribs. For $\alpha=90 \mathrm{deg}$, the heat/mass transfer enhancement with the discrete ribs is remarkable, while the heat/mass transfer performances are slightly higher than that of the transverse continuous ribs due to the accompanied high friction loss penalty. For $\alpha=45 \mathrm{deg}$, the average heat/mass transfer coefficients and the heat/mass transfer performances decrease slightly with the discrete ribs compared to the case of the angled continuous ribs.

This work extends the investigation carried out in the previous paper of Manca et al. (2010) but considering a three-dimensional model. The main aim of the present analysis is to investigate the flow and the heat transfer characteristics of a three-dimensional rib-roughned rectangular duct with the upper and bottom walls subjected to uniform heat flux by means of Fluent v6.3 code (2006). Ribs are provided on the heated walls. The aim is to generate friction and heat transfer data, for different values of Reynolds numbers in the range between 20000 and 60000 and different inclination angles from to $0^{\circ}$ to $33^{\circ}$. Ribs are rectangular and a dimensionless pitch of 15 has been considered.

\section{MATHEMATICAL MODEL AND GOVERNING EQUATIONS}

A computational fluid-dynamic analysis of a three-dimensional rectangular duct model, provided with different shaped ribs, as reported in Fig. 1, is considered in order to evaluate its thermal and fluiddynamic performances and study the temperature and velocity fields. A constant heat flux is applied uniformly on the external surface. Different inlet velocities are considered in the range of turbulent regime and the working fluid is air. The thermal properties of the fluid are considered dependent on temperature. The governing equations of continuity, momentum and energy are solved for a steady state turbulent flow in rectangular coordinates:

$\frac{\partial}{\partial x_{i}}\left(\rho u_{i}\right)=0$

$\frac{\partial}{\partial x_{j}}\left(\rho u_{i} u_{j}\right)=-\frac{\partial P}{\partial x_{i}}+\frac{\partial}{\partial x_{j}}\left[\mu\left(\frac{\partial u_{i}}{\partial x_{j}}+\frac{\partial u_{j}}{\partial x_{i}}-\frac{2}{3} \delta_{i j} \frac{\partial u_{i}}{\partial x_{j}}\right)\right]$

$+\frac{\partial}{\partial x_{j}}\left(-\rho \overline{u_{i}^{\prime} u_{j}^{\prime}}\right)$

$\frac{\partial}{\partial x_{i}}\left[u_{i}(\rho E+P)\right]=\frac{\partial}{\partial x_{j}}\left[\left(\lambda+\frac{c_{p} \mu_{t}}{\operatorname{Pr}_{t}}\right) \frac{\partial T}{\partial x_{j}}+u_{i}\left(\tau_{i j}\right)_{e f f}\right]$

where $E$ is the total energy, $E=c_{p} T-\frac{P}{\rho}+\frac{u^{2}}{2}$ and $\left(\tau_{\mathrm{ij}}\right)_{\mathrm{eff}}$ is the deviatoric stress tensor, defined as

$\left(\tau_{i j}\right)_{e f f}=\mu_{e f f}\left(\frac{\partial u_{j}}{\partial x_{i}}+\frac{\partial u_{i}}{\partial x_{j}}\right)-\frac{2}{3} \mu_{e f f} \frac{\partial u_{i}}{\partial x_{i}} \delta_{i j}$

The transport equations for the Shear-Stress Transport k- $\omega$ model are reported in the form, developed by Menter (1994)]:

$\frac{\partial}{\partial x_{i}}\left(\rho k u_{i}\right)=\frac{\partial}{\partial x_{j}}\left(\Gamma_{k} \frac{\partial k}{\partial x_{j}}\right)+\widetilde{G}_{k}-Y_{k}+S_{k}$

and

$\frac{\partial}{\partial x_{i}}\left(\rho \omega k u_{i}\right)=\frac{\partial}{\partial x_{j}}\left(\Gamma_{\omega} \frac{\partial \omega}{\partial x_{j}}\right)+G_{\omega}-Y_{\omega}+D_{w}+S_{\omega}$

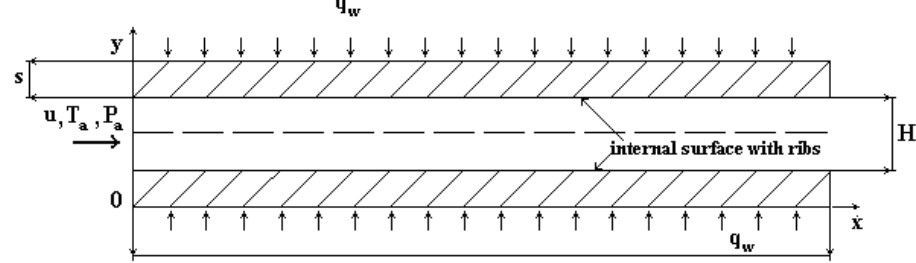

L

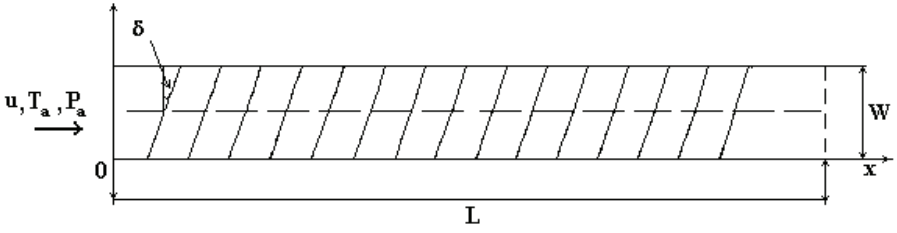

Fig. 1 Views of the geometrical model.

$G_{k}$ is the production of turbulence kinetic energy due to mean velocity gradients, $G_{\omega}$ represents the generation of $\omega$.

$\widetilde{G}_{k}=\min \left(G_{k}, 10 \beta^{*} k \omega\right)$

with $G_{k}=-\rho u_{i}^{\prime} u_{j}^{\prime} \frac{\partial u_{j}}{\partial x_{i}}$

$G_{\omega}=\frac{\alpha}{v_{t}} G_{k}$

where $v_{t}$ is the kinematic turbulent viscosity and $\beta^{*}$ a model constant; $\alpha$ is given by

$\alpha=\frac{\alpha_{\infty}}{\alpha} \frac{\left(\alpha_{0}^{*}+\operatorname{Re}_{t} / \operatorname{Re}_{w}\right)}{\left(1+\operatorname{Re}_{t} / \operatorname{Re}_{w}\right)}$

where $R_{\omega}=2.95, \beta_{l}=0.072$ and $\alpha$ is represented by

$\alpha_{\infty}=F_{1} \alpha_{\infty, 1}+\left(1-F_{1}\right) \alpha_{\infty, 2}$

$\alpha_{\infty, 1}=\frac{\beta_{i, 1}}{\beta_{\infty}^{*}}-\frac{\kappa^{2}}{\sigma_{\omega, 1} \sqrt{\beta_{\infty}^{*}}}$

$\alpha_{\infty, 1}=\frac{\beta_{i, 2}}{\beta_{\infty}^{*}}-\frac{\kappa^{2}}{\sigma_{\omega, 2} \sqrt{\beta_{\infty}^{*}}}$

where $\kappa=0.41$. In the High-Reynolds number form, $\alpha=\alpha_{\infty}=1.0 . \Gamma_{k}$ and $\Gamma_{\omega}$ represent the effective diffusivity of $k$ and $\omega$.

$\Gamma_{k}=\mu+\frac{\mu_{t}}{\sigma_{k}}$

$\Gamma_{\omega}=\mu+\frac{\mu_{t}}{\sigma_{\omega}}$

where $\sigma_{\mathrm{k}}$ and $\sigma_{\mathrm{w}}$ are the turbulent Prandtl numbers for $k$ and $\omega$, respectively:

$$
\begin{gathered}
\sigma_{k}=\frac{1}{F_{1} / \sigma_{k, 1}+\left(1-F_{1}\right) / \sigma_{k, 2}} \\
\sigma_{w}=\frac{1}{F_{1} / \sigma_{w, 1}+\left(1-F_{1}\right) / \sigma_{w, 2}}
\end{gathered}
$$

and $\mu_{t}$ is the turbulent viscosity, computed from:

$\mu_{t}=\alpha^{*} \frac{\rho k}{\omega}$

The coefficient $\alpha^{*}$ dampens the turbulent viscosity. It is given by

$\alpha^{*}=\alpha_{\infty}^{*} \frac{\left(\alpha^{*}{ }_{0}+\operatorname{Re}_{t} / \operatorname{Re}_{k}\right)}{\left(1+\operatorname{Re}_{t} / \operatorname{Re}_{k}\right)}$

where $R e_{t}=\rho k / \mu \omega, R_{k}=6, \alpha^{*}{ }_{0}=\beta_{i} / 3$ and $\beta_{l}=0.072$. In the highReynolds number form $\alpha^{*}=\alpha^{*}{ }_{\infty}=1.0$. The blending equation $F_{l}$ is given by 


$$
\begin{aligned}
& F_{1}=\tan \left(\Phi_{1}{ }^{4}\right) \\
& \Phi_{1}=\min \left[\max \left(\frac{\sqrt{k}}{0.09 \omega y}, \frac{500 \mu}{\rho y^{2} \omega}\right), \frac{4 \rho k}{\sigma_{w, 2} D_{\omega}{ }^{+} y^{2}}\right] \\
& D_{\omega}{ }^{+}=\max \left[2 \rho \frac{1}{\sigma_{\omega, 2}} \frac{1}{\omega} \frac{\partial k}{\partial x_{j}} \frac{\partial w}{\partial x_{j}}, 10^{-10}\right]
\end{aligned}
$$

where $y$ is the distance to the next surface and $D_{\omega}{ }^{+}$is the positive portion of the cross-diffusion term. $Y_{k}$ and $Y_{\omega}$ represent the dissipation of $k$ and $\omega$ due to turbulence:

$$
\begin{aligned}
& Y_{k}=\rho \beta^{*} k \omega \\
& Y_{\omega}=\rho \beta \omega^{2}
\end{aligned}
$$

with $\beta$ and $\beta^{*}$ are model constants; moreover

$\beta_{i}=F_{1} \beta_{i, 1}+\left(1-F_{1}\right) \beta_{i, 2}$

$D_{\omega}$ represents the cross- diffusion term while $S_{k}$ and $S_{\omega}$ are possible source terms. In particular, $D_{\omega}$ is given by

$D_{\omega}=2\left(1-F_{1}\right) \rho \sigma_{\omega, 2} \frac{1}{\omega} \frac{\partial k}{\partial x_{j}} \frac{\partial \omega}{\partial x_{j}}$

The turbulent model constants are summarized in tab.1:

Table 1 Shear Stress Transport $k$ - $\omega$ model constants.

\begin{tabular}{|l|l|l|l|l|}
\hline$\sigma_{K, 1}=1.176$ & $\sigma_{K, 2}=1.0$ & $\sigma_{\omega, 1}=2.0$ & $\sigma_{\omega, 2}=1.168$ & $\alpha_{1}=0.31$ \\
\hline$\beta_{i, 1}=0.075$ & $\beta_{i, 2}=0.0828$ & $\alpha_{\infty}^{*}=1.0$ & $\alpha_{\infty}=0.52$ & $\beta_{\infty}^{*}=0.09$ \\
\hline$\beta_{i}=0.072$ & $\alpha_{0}=1 / 9$ & $R_{\beta}=8.0$ & $R_{K}=6.0$ & $R_{\omega}=2.95$ \\
\hline$\zeta^{*}=1.5$ & $\sigma_{K}=2.0$ & $\sigma_{\omega}=2.0$ & & \\
\hline
\end{tabular}

A three-dimensional conduction model in heated walls is employed in the steady-state regime. The working fluid is air and its properties are considered temperature dependent.

\section{GEOMETRICAL DESCRIPTION}

The three-dimensional rectangular duct model, depicted in Fig. 1, has a length, $L$, equal to $250 \mathrm{~mm}$ while the height $H$ is set equal to $33.3 \mathrm{~mm}$ and width $W$ is $100 \mathrm{~mm}$; the hydraulic diameter, $d_{h}=4 A / P_{h}=$ $2 H W /(H+W)$, is equal to $50 \mathrm{~mm}$. The $3 \mathrm{~mm}$ thick wall is made up by aluminium and a constant heat flux equal to $10 \mathrm{~kW} / \mathrm{m}^{2}$ has been applied on the upper and bottom walls which are provided with ribs. On these walls rectangular ribs are introduced and they are characterized by an aspect ratio $w / e$ equal to 0.5 .

Four rib angles $(\delta)$, related to the $x-z$ plane, are considered. The roughness parameters, reported in Fig.2, are determined by rib height $(e)$, rib pitch $(p)$, rib width $(w)$, and the shape of roughness elements. These parameters are expressed in the form of the following dimensionless roughness parameters: relative roughness pitch, $p / e$; relative roughness height, $e / d_{h}$; relative roughness width, $w / e$.

For a specific roughness type, a family of geometrically similar roughness is possible to identify by changing $e / d_{h}$ ratio while maintaining constant $p / e$ and $w / e$.

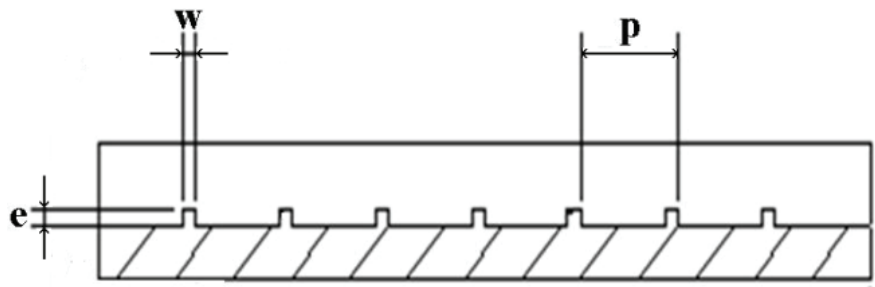

Fig. 2 Characteristic rib parameters.
In this analysis, the range of dimensionless roughness parameters for the rectangular ribs and Reynolds numbers employed in this investigation are given below:

- $\quad$ Reynolds number, Re: from 20000 to 60000 ;

- Relative roughness pitch, $p / e: 15$;

- Dimensionless height, $e / d_{h: 0.02 .}$

- Inclination angle, $\delta: 0^{\circ}, 11^{\circ}, 22^{\circ}$ and $33^{\circ}$.

The dimensionless parameters, here considered, are:

$$
\begin{aligned}
& \operatorname{Re}=\frac{u_{a v} d_{h}}{v} \\
& N u_{a v}=\frac{\dot{q} d_{h}}{\left(T_{w}-T_{m}\right) \lambda_{f}} \\
& f=2 \Delta P \frac{d_{h}}{L} \frac{1}{\rho u^{2}}
\end{aligned}
$$

\section{NUMERICAL MODEL AND VALIDATION}

Governing equations of continuity, momentum and energy are solved by the finite volume method in the steady-state regime. A segregrated method is chosen to solve the governing equations, which are linearized implicitly with respect to dependent variables of the equation. A second-order upwind scheme is chosen for energy and momentum equations. The SIMPLE Coupling is chosen as scheme to couple pressure and velocity. The convergence criteria of $10^{-5}$ for the residuals of the velocity components and of $10^{-8}$ for the residuals of the energy are assumed.

It is assumed that the incoming flow is in fully turbulent conditions at different uniform velocities, corresponding to Reynolds numbers ranging from 20000 to 60000 , and at the ambient temperature $\left(T_{a}=300\right.$ $\mathrm{K})$ and pressure. Along the solid walls no slip condition is employed whereas a velocity inlet and outflow conditions are given for the permeable walls.

Four different grid distributions are tested on rectangular ribs, with $p / e=15, e / d_{h}=0.02$ and $w / e=0.5$, to ensure that the calculated results are grid independent. They have 27000, 55400, 108100 and 189900 nodes, respectively. The grid mesh is structured in each case with grid adoption for $\mathrm{y}^{+}=1$ at adjacent wall region.

Comparing the second and third mesh configuration differences of $0.25 \mathrm{~K}, 0.015 \mathrm{~K}, 0.008 \mathrm{~m} / \mathrm{s}, 3.0 \mathrm{~Pa}$ are evaluated in terms of wall average temperature, mass-weighted average outlet temperature, average outlet velocity and pressure drops. So the second grid case has been adopted because it ensured a good compromise between the machine computational time and the accuracy requirements. Results are validated by comparing the obtained numerical data with the numbers calculated using the following correlations for Nusselt numbers and friction coefficients:

Dittus-Boelter: $N u_{s}=0.024 \operatorname{Re}^{0.8} \operatorname{Pr}^{0.4}$

for: $0.5<\operatorname{Pr}<120,6.0 \times 10^{3}<\operatorname{Re}<1.0 \times 10^{7} ; 60<(L / d)$

Petukhov: $N u_{s}=\frac{\operatorname{Re} \operatorname{Pr} f / 8}{1.07+12.7(f / 8)^{1 / 2}\left(\operatorname{Pr}^{2 / 3}-1\right)}$

with

$f_{S}=\left(1.84 \log _{10} \operatorname{Re}-1.64\right)^{-2}$

for: $0.5<\operatorname{Pr}<200,1.0 \times 10^{4}<\operatorname{Re}<5.0 \times 10^{6}$;

Gnielinski: $N u_{s}=\frac{\operatorname{Re} \operatorname{Pr} f / 8}{1.07+12.7(f / 8)^{1 / 2}\left(\operatorname{Pr}^{2 / 3}-1\right)}$

with

$f_{S}=\left(0.79 \log _{10} \mathrm{Re}-1.64\right)^{-2}$

for: $0.5<\operatorname{Pr}<200,1.0 \times 10^{4}<\operatorname{Re}<5.0 \times 10^{6}$;

McAdams: $f_{s}=0.184 \mathrm{Re}^{-0.2}$ 
Figure 3 and Figure 4 presents the comparison with literature data in terms of average Nusselt number and friction factor for the smooth channel. There is a very good correspondence with the correlations in terms of average Nusselt number, as reported in Fig. 4. The Nusselt number differences are more valuable comparing results with DittusBoelter correlation for high Reynolds numbers. For $R e=60000$, in fact, the Nusselt number has a percentage error of $10 \%$. Figure 4 shows the results in terms of friction factors. It is found that the percentage error is very little and curves fit with the experimental one very good. A difference of $3.5 \%$ has been calculated at most by comparing results with ones for Petukhov correlation.

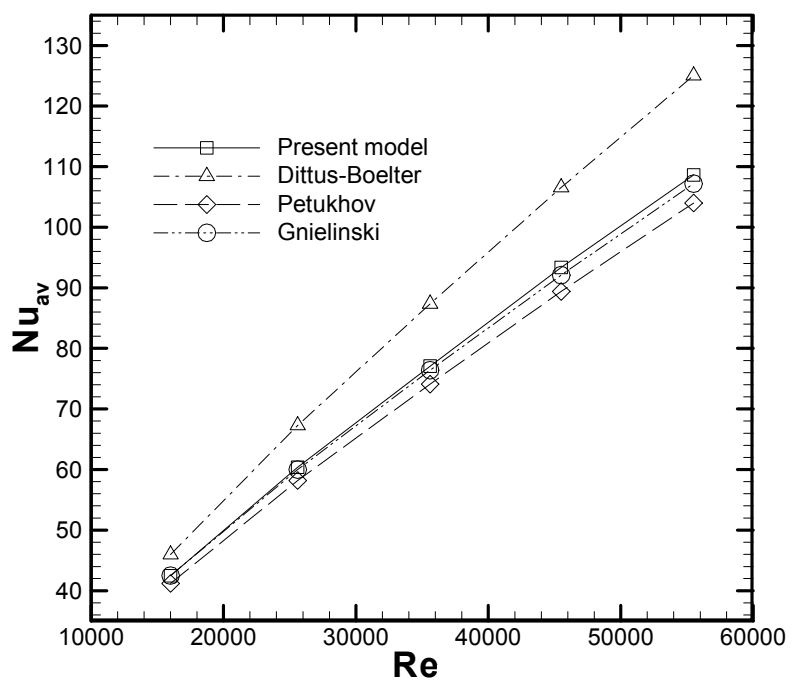

Fig. 3 Validation of results in terms of Nusselt number.

\section{RESULTS AND DISCUSSION}

Results are presented in form of graphs, representing the average Nusselt number and friction factors, the dimensionless temperature at the outlet section, the local Nusselt number at a rib near the outlet section, at different angles, $\delta$, and Reynolds numbers, and in form of temperature and velocity contours at particular sections for a fixed Reynolds number. Ribs are characterized by a rectangular shape with values of $w / e, e / d_{h}$ and $p / e$ ratios, equal to $0.5,0.02$ and 15, respectively.

Figure 5 presents the average Nusselt number profiles, referred to the smooth channel, for different angles $\delta$ and Reynolds numbers. It is shown that the $N u_{a v} / N u_{a v, s}$ ratio increases as the angle $\delta$ increases in the considered range. This behaviour is due to the turbulence emphasized by the presence of angled ribs. For example, at $R e=40000$, in the case of $\delta=33^{\circ}$, the average Nusselt number is about $20 \%$ higher than the one, calculated for the configuration with transverse ribs. The heat transfer rate, obviously, grows as Reynolds number increases, too. At most the average Nusselt number ratio augments 1.65 times in comparison with the results for smooth channel.

In Fig. 6 the dimensionless temperature profiles, evaluated at the outlet section, for different Reynolds number and angles $\delta$ are carried out. The dimensionless temperature, $T^{*}$ out has been referred to the smooth channel and evaluated as:

$T^{*}{ }_{\text {out }}=\frac{T-T_{a}}{T_{s}-T_{a}}$

It is shown that $T^{*}{ }_{\text {out }}$ increases as Reynolds number increases. In fact, at $R e=60000$ for $\delta=0^{\circ}$ a slight growth, in terms of dimensionless outlet temperature, in comparison with the smooth channel results, is noticed. Temperature increases significantly by changing the angle $\delta$; in fact, at $R e=60000$ for $\delta=33^{\circ}, T^{*}{ }_{\text {out }}$ is clearly increased of about $22 \%$. At $\delta=11^{\circ} T^{*}{ }_{\text {out }}$ is about 1.16 times higher than the smooth channel values.

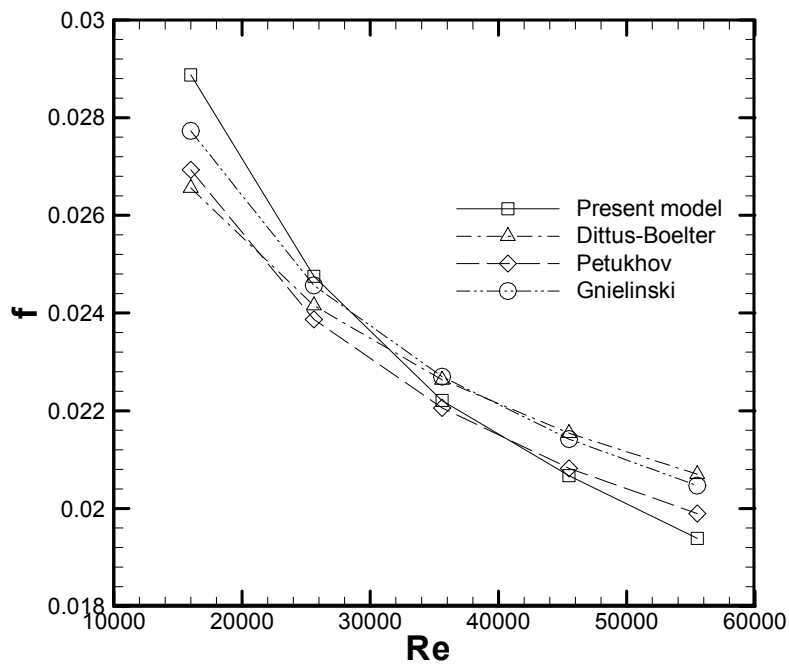

Fig. 4 Validation of results in terms of friction factors.

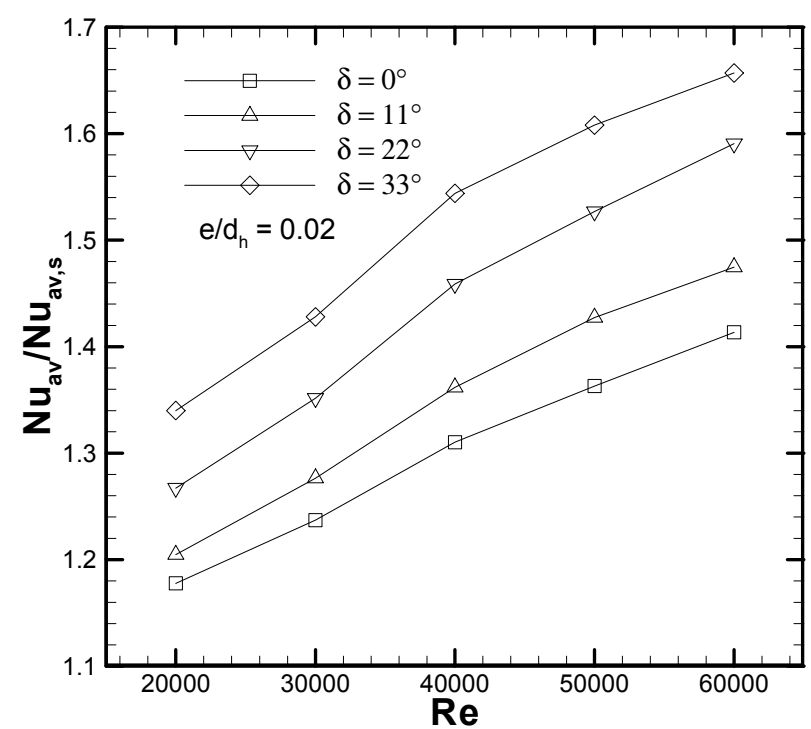

Fig. 5 Average Nusselt number profiles, referred to the smooth channel, for different angles $\delta$ and Reynolds number at $e / d_{h}=0.02$ and $p / e=15$.

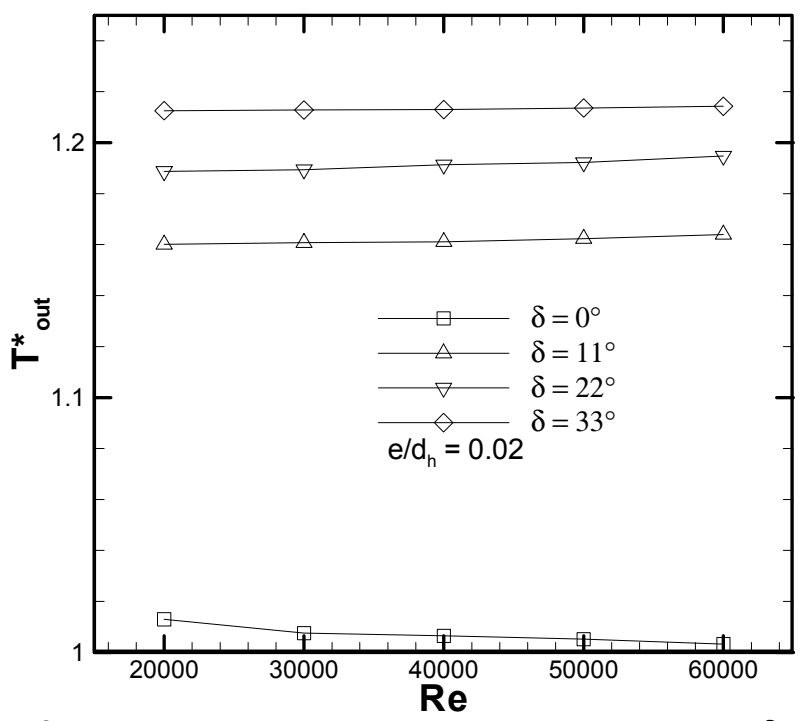

Fig. 6 Dimensionless temperature profiles for different angles $\delta$ and Reynolds number at $e / d_{h}=0.02$ and $p / e=15$ at the outlet section. 
However, losses increase as well, as reported in Figs. 7-8. Figure 7 shows the results in terms of friction factors, referred to the smooth channel at different Reynolds numbers and inclination angle. The $f / f_{s}$ ratio increases as the Reynolds number and angle $\delta$ augment. At $R e=$ 40000 and for $\delta=33^{\circ}$, this ratio is 1.24 times higher than one, calculated for $\delta=0^{\circ}$.

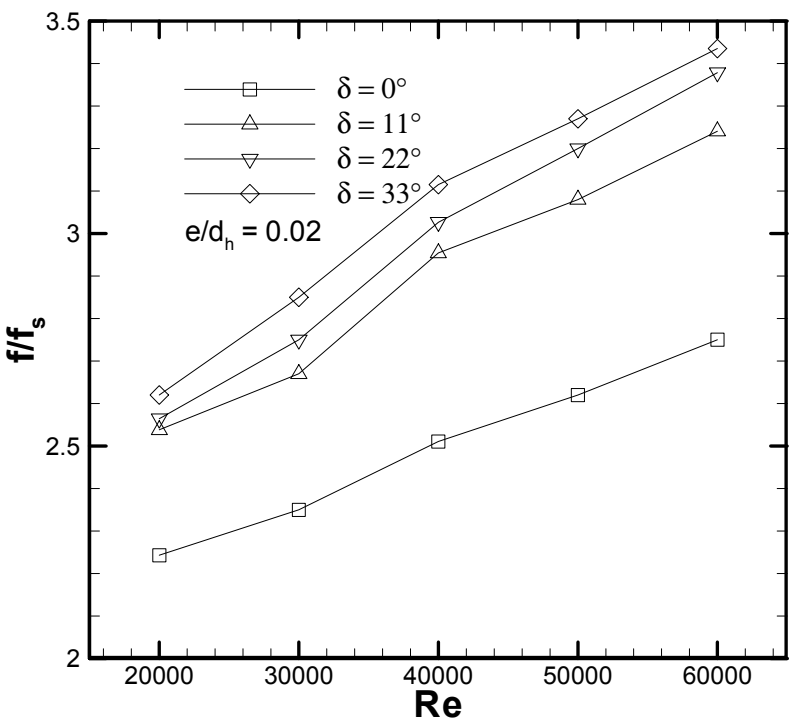

Fig. 7 Friction factor profiles for different angles $\delta$ and Reynolds number at $e / d_{h}=0.02$ and $p / e=15$ referred to the smooth channel.

Figure 8 presents the results in terms of the required pumping power ratio, referred to the smooth configuration results. Profiles grow as $R e$ and $\delta$ increases, as expected.

If the Fig. 9 is observed, it is evident that when Reynolds number increases, $f$ clearly increases until $R e=40000$ then it seems to tend to an asymptotic value also for $\delta>0^{\circ}$, as regarded for the transverse ribs cases.

Figure 10 summarizes the obtained results in terms of $P E C$ index, given by

$P E C=\frac{\left(\mathrm{Nu} / \mathrm{Nu} u_{s}\right)}{\left(f / f_{s}\right)^{1 / 3}}$

$P E C$ index is greater than 1 for all the considered cases.

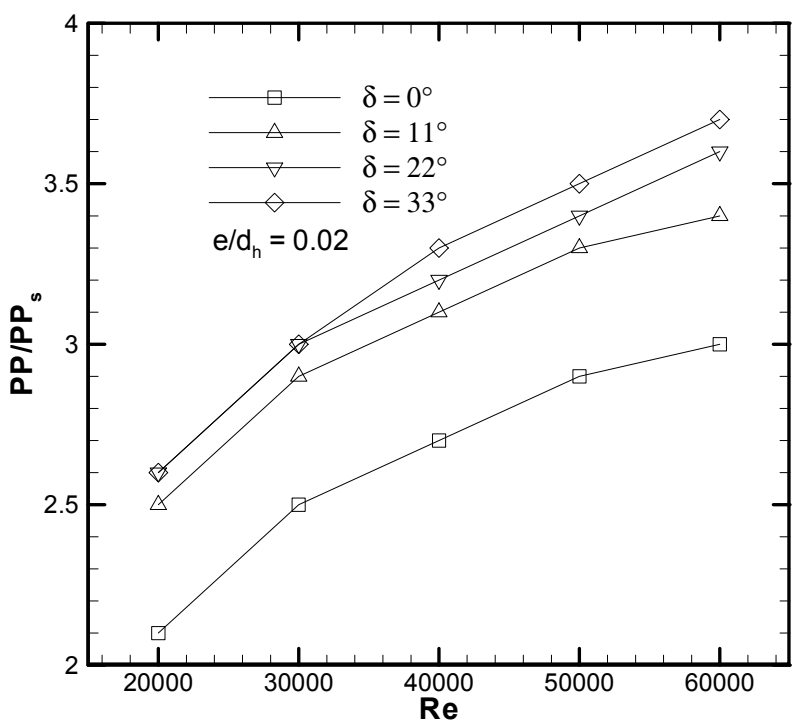

Fig. 8 Profiles of required pumping power, for different angles $\delta$ and Reynolds number at $e / d_{h}=0.02$ and $p / e=15$.

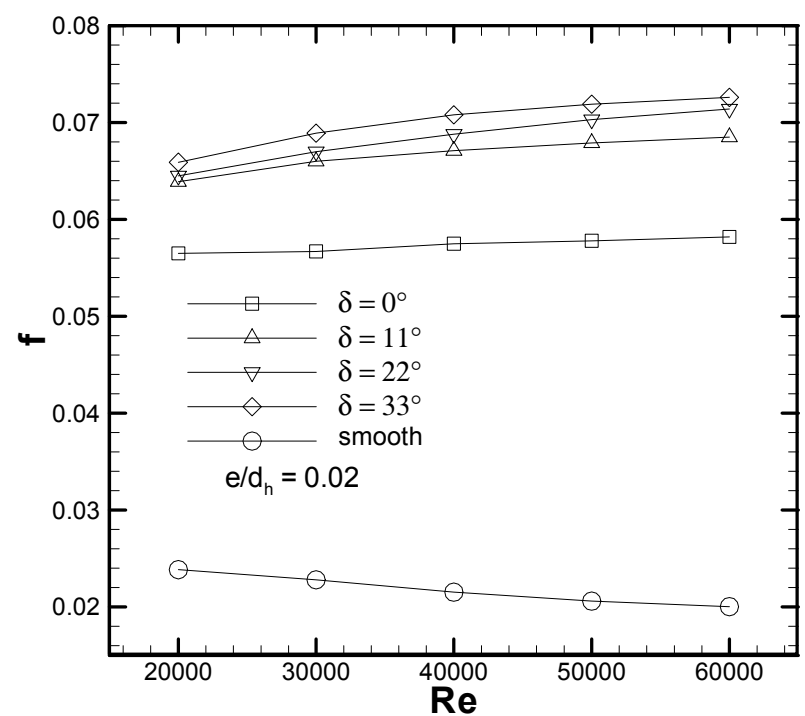

Fig. 9 Friction factor profiles for different angles $\delta$ and Reynolds number at $e / d_{h}=0.02$ and $p / e=15$.

However, it decreases as $R e$ reduces. In fact, maxima are evaluated at $R e=20000$; at this $R e$ the highest value is calculated for $\delta=0^{\circ}$ and it is equal to 1.53 while the minimum one is observed for $\delta=11^{\circ}$. For $\delta>$ $11^{\circ}$, the index tends to increase and it is equal to 1.43 and 1.48 , at $\delta=$ $22^{\circ}$ and $33^{\circ}$, respectively. For $R e=60000$, the $P E C$ values are in the range $1.16-1.32$, corresponding to $\delta=11^{\circ}$ and $0^{\circ}$, respectively.

Figure 11 shows the results in terms of local Nusselt number profiles at different $x / e$ values for a rib region, near to the outlet section, at $z / W=0.1$ and 0.5 . It is easily observed that Nusselt number profiles change when it is calculated at different positions along z. Near the adiabatic smooth wall, at $z / W=0.1$, the highest values are obtained for large angles; on the contrary, the highest heat transfer rate are evaluated for $\delta=0^{\circ}$ at $z / W=0.5$, such as in correspondence with the symmetry axis, as depicted in Figure 11b. However, the highest values of local Nusselt numbers is observed at $\mathrm{x} / \mathrm{e}$ equal to about $5-6$, such as near the point of reattachment of the fluid flow, deflected by the presence of the angled ribs.

Figure 12 depicts the flow pattern for a Reynolds number equal to 40000 , in correspondence with the zones near the outlet region for a $\mathrm{x}-\mathrm{Z}$ plane section at $\mathrm{z} / \mathrm{W}=0.25$.

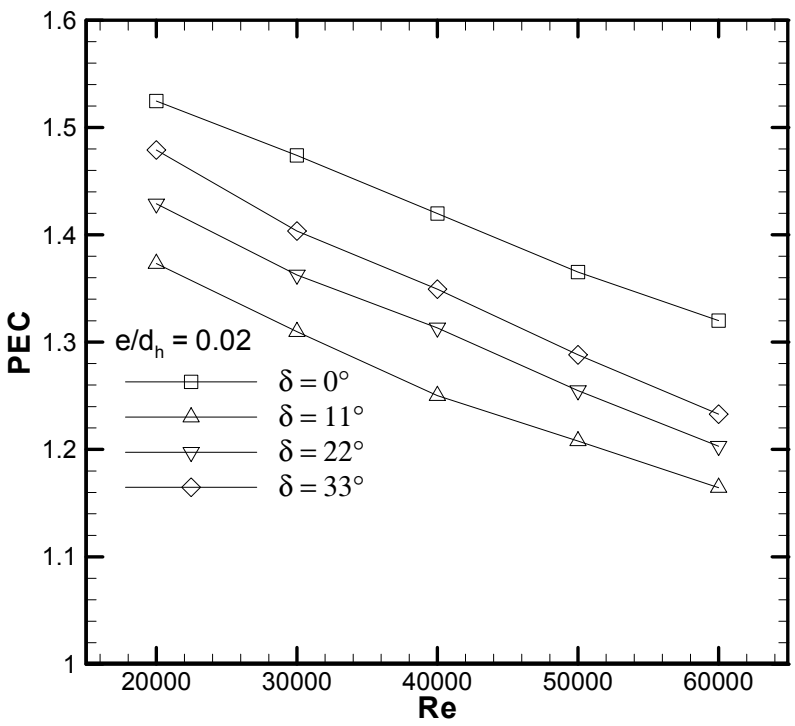

Fig. $10 P E C$ index profiles for different angles $\delta$ and Reynolds number at $e / d_{h}=0.02$ and $p / e=15$ at the outlet section. 


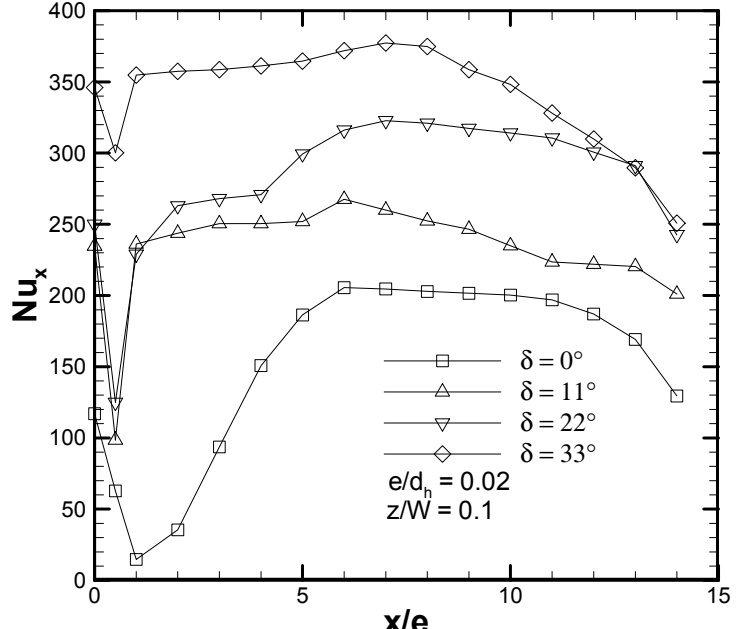

a)

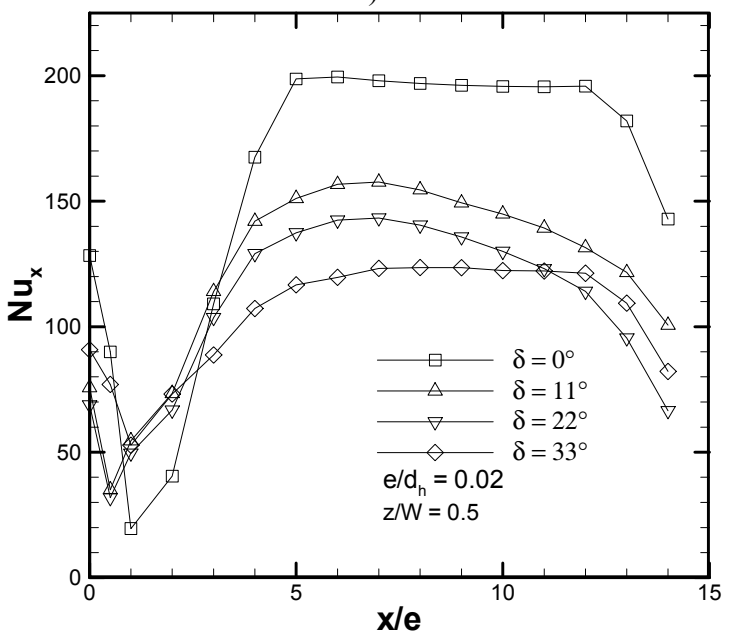

b)

Fig. 11 Local Nusselt number profiles, in correspondence of a rib near to the outlet section, for different angles $\delta$ and Reynolds number equal to 60000 at $e / d_{h}=0.02$ and $p / e=15$ : a) $z / W=0.1$; b) $z / W=0.5$.

Fig 12a depicts the flow pattern for $\delta=0^{\circ}$, such as the case with ribs, orthogonal to the flow direction, in order to clearly show the eddy formation, adjacent to the rib when the flow is stabilized. As reported in a previous analysis, after 4-5 ribs the fluid results to be 'stabilized', such as the vortex structures between two adjacent cells repeat almost similarly (Manca et al., 2010).

In this paper a dimensionless pitch, $p / \mathrm{e}$, equal to 15 has been considered. Consequently, a $k$-type roughness behavior may be detected by observing the velocity fields, reported below. As underlined by Manca et al., in fact, due to the presence of the rib surfaces, the fluid flow is deflected and reattaches downstream after 5-6 times the dimensionless height of turbulators. The length scale for $k$-type is the roughness height, so the eddies with length scale of the order of the roughness height are shed from roughness elements and penetrate into the bulk flow toward boundary layer, and the roughness function and friction factor depend on the size of roughness elements. The heat transfer rate results to be increased because the flow turbulence is more significant and, secondly, the heat transfer surface augments.

If $\delta$ angle increases, ribs are no more orthogonal to the flow main direction and a significant turbulence may be promoted along z-plane, according to the considered angle of inclination. In fact, in Fig. 12b a slight differences of the vortex structures in the inter-rib region are shown. The eddy distortion is more evident in Fig. 12c, which describes how the bulk flow is clearly influenced by the presence of the turbulators.

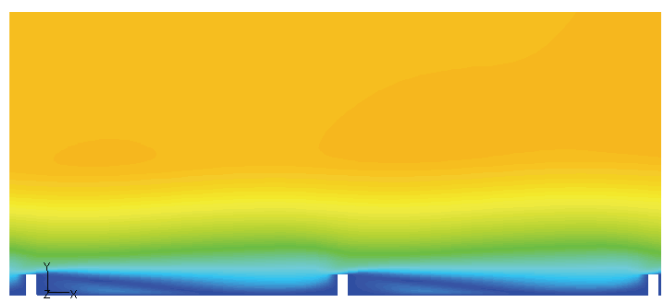

a)

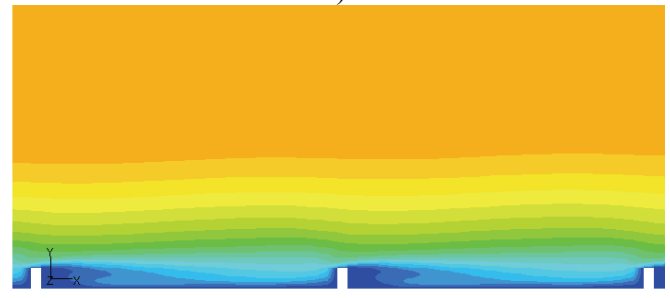

b)

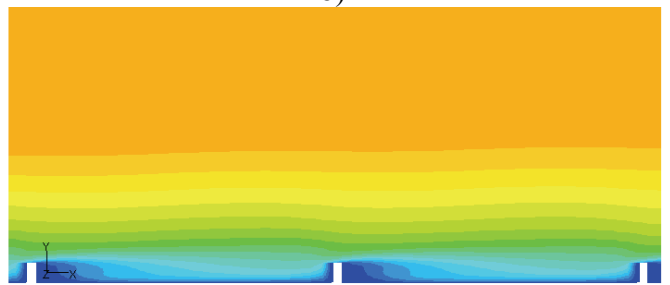

Fig. 12 Velocity contours for $R e=40000$ near the outlet section, plane $\mathrm{x}-\mathrm{y}$ at z $/ \mathrm{W}=0.25$ : a) $\delta=0^{\circ}$; b) $\delta=22^{\circ}$; c) $\delta=33^{\circ}$.

Figure 13 is referred to the velocity field for $R e=40000$ at the outlet section in correspondence with the $y-z$ plane view. Comparing Figs. 13a and $13 \mathrm{~b}$, which correspond to the configuration with $\delta=0^{\circ}$ and $\delta=33^{\circ}$, respectively, it is clear how the inclination of the ribs influences the air motion at the outlet section, too.

Figure 14 describes the temperature fields near the outlet region for $R e=20000$ in correspondence with an $\mathrm{x}-\mathrm{y}$ plane section at $z / W=$ 0.25 , considering different inclination angles. Fig. 14a displays an augment of heat transfer coefficient and a secondary recirculation zone is formed near the rib-wall juncture behind the rib and the substrate temperature under this region becomes very high. The fluid in the secondary recirculation is heated, sometimes hotter than the rib itself, and the heat flows from the air to the solid. Moreover, figure shows that the temperature is lowest on the windward face of the rib, and highest on the leeward face, while heat flux is highest on the front face and lowest on the back face. By increasing the inclination angle, the surface temperature decreases and the bulk flow one increases, because of higher heat transfer rates as reported in Figs. 14b and 14c. The thermally influenced zone near the ribs and inter-rib regions tends to reduced because the heat transfer is more efficient as clearly observed in Fig. 12c.
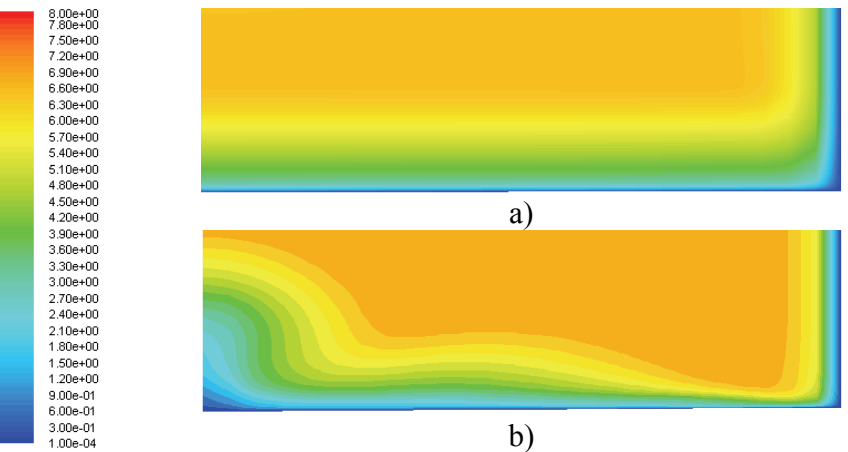

a)

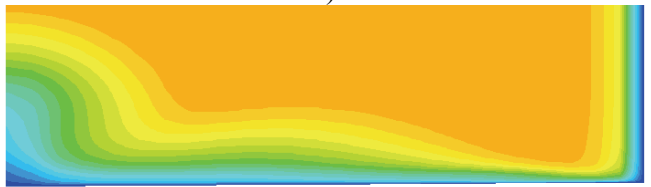

b)

Fig. 13 - Velocity contours for $R e=40000$ at the outlet section, plane y-z: a) $\delta=0^{\circ}$; b) $\delta=33^{\circ}$. 


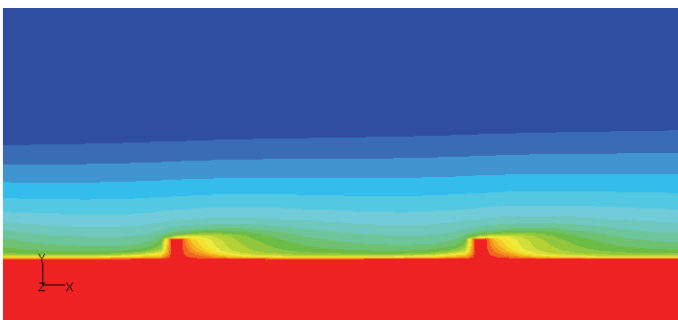

a)

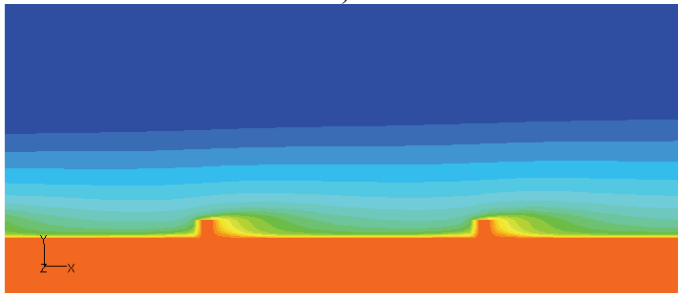

b)

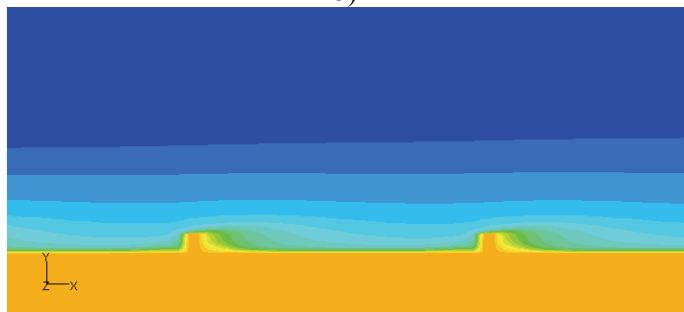

c)

Figure 14 Temperature fields for $R e=20000$ near the outlet section, plane x-y at z $/ \mathrm{W}=0.25$ : a) $\delta=0^{\circ}$; b) $\delta=11^{\circ}$; c) $\delta=33^{\circ}$.

Figure 15 presents the temperature fields in $\mathrm{x}-\mathrm{y}$ plane section view at $z / W$ ratio equal to 0.5 for $R e=20000$ and $\delta=11^{\circ}$ and $33^{\circ}$. Some differences are observed in the temperature fields; in particular, the thermally affected zone near the ribs and inter-rib regions is larger, comparing Figs. 15a and 15b with Figs. 14b and 14c. This behavior is related to a lower heat transfer rate in these zones.

Figure 16 is referred to the outlet section in the plane $y-z$ and remarks the influence of the inclination angles on the temperature fields. In fact, in Fig. 16b the fluid temperature augmentation, due to the increased mixing effect related to large inclination angles is very significant.
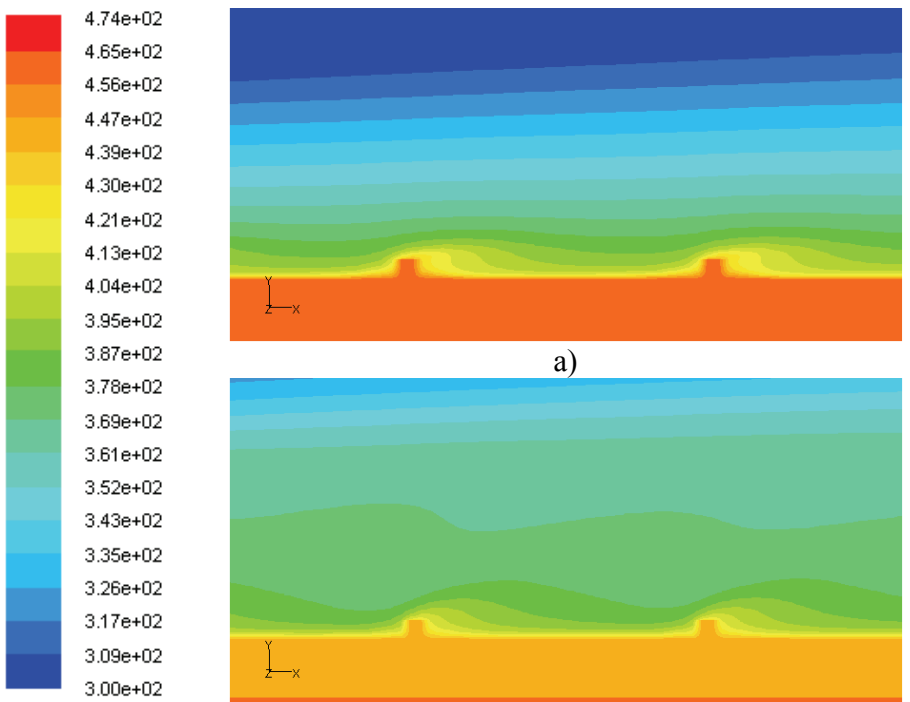

a)

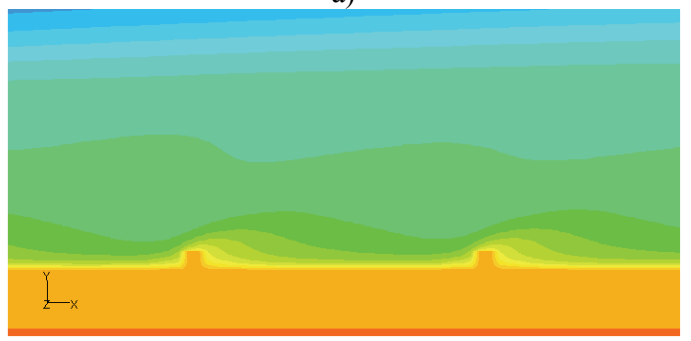

b)

Fig. 15 Temperature fields for $R e=20000$ near the outlet section, plane $\mathrm{x}-\mathrm{y}$ at $\mathrm{z} / \mathrm{W}=0.5$ : a) $\delta=11^{\circ}$; b) $\delta=33^{\circ}$.
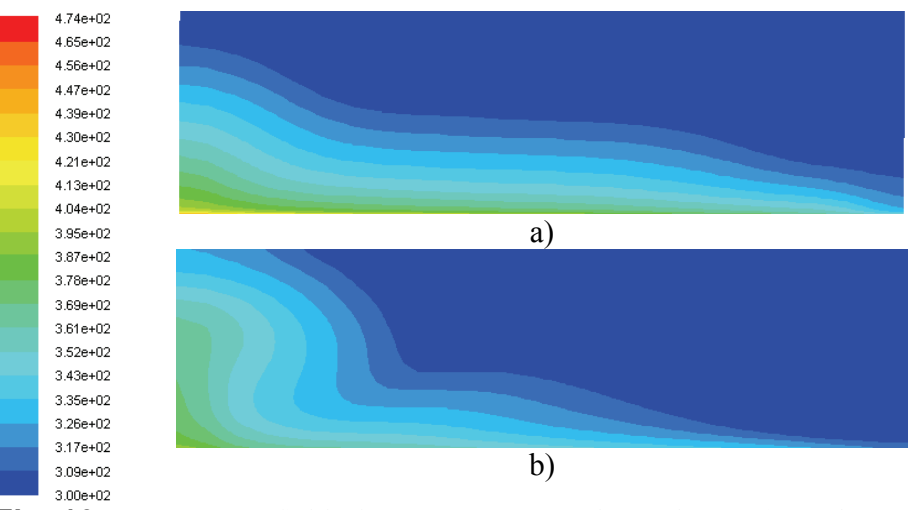

a)

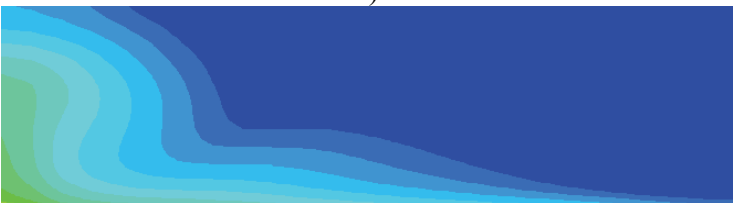

b)

Fig. 16 Temperature fields for $R e=20000$ at the outlet section, plane yz: a) $\delta=0^{\circ}$; b) $\delta=33^{\circ}$.

\section{CONCLUSIONS}

In this paper a three-dimensional rectangular channel, provided with rectangular ribs and heated by a constant heat flux equal to $10 \mathrm{~kW} / \mathrm{m}^{2}$, applied on the ribbed walls. Different inclination angles $\left(\delta=0^{\circ}, 11^{\circ}\right.$, $22^{\circ}$ and $33^{\circ}$ ) of turbulators have been considered. Numerical simulations, regarding a dimensionless pitch equal to 15 and dimensionless height equal to 0.02 have been carried out by means of FLUENT code. The aim of the investigation consists into find out the optimal angle of ribs at different Reynolds number, between 20000 and 60000 , in order to ensure maximum heat transfer rate and reduced drops.

Simulations show that maximum Nusselt numbers are detected by increasing the $\delta$ angles. In fact, the heat transfer rate is 1.34 times higher than the smooth duct at least at $\mathrm{Re}=20000$; furthermore, the friction factor is the highest at the largest considered angles and, in particular, its value is 3.5 times greater at most. For $\mathrm{Re}>40000$ an asymptotic behavior is detected. Finally, temperature fields and stream function contours are given in order to visualize the temperature distribution and flow pattern in presence of k-type roughness behavior and describe the influence of the rib inclination angle.

\section{ACKNOWLEDGEMENTS}

This work was supported by SUN with a 2008 grant and by MIUR with Articolo D.M. 593/2000 Grandi Laboratori "EliosLab".

\section{NOMENCLATURE}

$a$

A

$c_{p}$

$d$

$e$

$f$

$h$

$H$

L

$\mathrm{Nu}$

$p$

$P$

$P r=v / a$

$q$

Re

$s$

$T$

$u$

w

W

$z, y, z$ thermal diffusivity $\left(\mathrm{m}^{2} / \mathrm{s}\right)$

cross section area $\left(\mathrm{m}^{2}\right)$

specific heat $(\mathrm{J} / \mathrm{kgK})$

diameter $(\mathrm{m})$

rib height $(\mathrm{m})$

friction coefficient

convective heat transfer coefficient

channel height $(\mathrm{m})$

channel length (m)

Nusselt number

rib pitch (m)

pressure $(\mathrm{Pa})$

Prandtl number

heat flux $\left(\mathrm{W} / \mathrm{m}^{2}\right)$

Reynolds number

channel thickness (m)

temperature $(\mathrm{K})$

velocity component $(\mathrm{m} / \mathrm{s})$

rib width (m)

channel width (m)

spatial coordinates $(\mathrm{m})$ 
Greek symbols

$\delta \quad$ rib inclination angle (deg)

$\delta_{i j} \quad$ Kronecker delta

$\lambda \quad$ thermal conductivity $(\mathrm{W} / \mathrm{mK})$

$\rho \quad$ density $\left(\mathrm{kg} / \mathrm{m}^{3}\right)$

$\sigma \quad$ turbulent Prandtl number

$\tau \quad$ wall shear stress $\left(\mathrm{kg} / \mathrm{m}^{2}\right)$

$v \quad$ kinematic viscosity $\left(\mathrm{s} / \mathrm{m}^{2}\right)$

$\begin{array}{ll}\text { Subscripts } & \\ a & \text { ambient } \\ a v & \text { average } \\ f & \text { fluid } \\ h & \text { hydraulic } \\ i & \text { internal } \\ m & \text { mass } \\ s & \text { smooth } \\ t & \text { turbulent } \\ w & \text { wall }\end{array}$

\section{REFERENCES}

Bergles, A.E., Rohsenow, W.M., Hartnett, J.P., and Ganie, E., 1985, "Techniques to Augment Heat Transfer", Handbook of Heat Transfer Application, McGraw Hill, New York.

Bergles, A.E., 1998, "Some Perspectives on Enhanced Heat Transfer, Second-generation Heat Transfer Technology," ASME Journal of Heat Transfer, 110, pp. 1082-1096.

doi: $10.1115 / 1.3250612$

Cho, H. H., Wu, S. J., and Kwon, H. J., 2000, "Local heat/mass transfer measurements in a rectangular duct with discrete ribs," Journal of Turbomachinery, 122, pp. 579-586.

doi:10.1115/1.1303049

Fluent corporation, 2006, Fluent v6.3 user guide.

Giupta, D., 1993, "Investigations on Fluid Flow and Heat Transfer in Solar Air Heaters with Roughened Absorbers," Ph. D. Thesis, University of Roorkee, India.

Iaccarino, G., Ooi, A., Durbin, P.A., and Behnia, M., 2002, "Conjugate Heat Transfer Prediction in Two Dimensional Ribbed Passages," International Journal of Heat and Fluid Flow, 23, pp. 340-345. doi:10.1016/S0142-727X(02)00181-9

Karwa, R., Solanky, S.C., and Saini, J.S., 1999, "Heat Transfer Coefficient and Friction Factor Correlations for the Transient Flow Regime in Rib-roughened Rectangular Ducts," International Journal of Heat and Mass Transfer, 42, pp. 1597-1615. doi:10.1016/S0017-9310(98)00252-X

Karwa, R., Solanky, S.C., and Saini, J.S., 2001, "Thermo-hydraulic Performance of Solar Air Heaters Having Integral Chamfered Rib Roughness on Absorber Plates," Energy, 26, pp.161-176.

doi:10.1016/S0360-5442(00)00062-1

Kiml, R., Mochizuki, S., and Murata, A., 2001, "Effects of rib arrangements on heat transfer and flow behavior in a rectangular ribroughened passage: Application to cooling of gas turbine blade trailing edge," Journal of Heat Transfer, 123, pp. 675-681.

doi:10.1115/1.1378019

Lee, B.K., Cho, N.H., and Choi, Y.D., 1988, "Analysis of Periodically Fully Developed Turbulent Flow and Heat Transfer by k- $\varepsilon$ Equation
Model in Artificially Roughened Annulus," International Journal of Heat and Mass Transfer, 31, pp. 1797-1806.

doi:10.1016/0045-7949(94)90314-X

Lee, C.K., and Abdel Moneim, S.A., 2001, "Computational Analysis of Heat Transfer in Turbulent Flow Past a Horizontal Surface with a 2-D Ribs," International Community of Heat and Mass Transfer, 26, pp. 161-176. doi:10.1016/S0735-1933(01)00223-8

Liou, T.M., and Hwang, J.J., 1993, "Effect of Ridge Shapes on Turbulent Heat Transfer and Friction in a Rectangular Channel," International Journal of Heat and Mass Transfer, 36, pp. 931-940. doi:10.1016/S0017-9310(05)80277-7

Liou, T.M., Hwang, J.J., and Chen, S.H., 1993, "Simulation and Measurement of Enhanced Turbulent Heat Transfer in a Channel with Periodic Ribs on One Principal Wall," International Journal of Heat and Mass Transfer, 36, pp. 507-517.

doi:10.1016/0017-9310(93)80025-P

Manca, O., Nardini, S., and Ricci, D., 2010, "Numerical Investigation of Air Forced Convection in Channels with Differently Shaped Transverse Ribs," International Journal of Numerical Methods for Heat and Fluid Flow, in press, art. no HFF-Dec-2009-0162.R1, ISSN : 09615539 .

Menter, F.R., 1994, "Two Equation Eddy-Viscosity Turbulence Models for Engineering Applications," AIAA Journal, 32, pp. 1598-1605. doi: $10.2514 / 3.12149$

Muluwork, K.B., Solanky, S.C., and Saini, J.S., 2000, "Study of Heat Transfer and Friction in Solar Air Heaters Roughened with Staggered Discete Ribs," Proceedings of the $4^{\text {th }}$ ISHMT-ASME Heat and Mass Transfer Conference, Pune India; pp. 391-398.

Ryu, D.N., Choi, D.H., and Patel, V.C., 2007, "Analysis of Turbulent Flow in Channels Roughened by Two-dimensional and Threedimensional Blocks. Part I: Resistance," International Journal of Heat and Fluid Flow, 28, pp. 1098-1111.

doi:10.1016/j.ijheatfluidflow.2006.11.006

Ryu, D. N., Choi, D. H., and Patel, V. C., 2007, “Analysis of Turbulent Flow in Channels Roughened by Two-dimensional and Threedimensional Blocks. Part II: Heat Transfer," International Journal of Heat and Fluid Flow, 28, pp. 1112-1124.

doi:10.1016/j.ijheatfluidflow.2006.11.007

Slanciauskas, A., 2001, "Two Friendly Roles for the Turbulent Heat Transfer Enhancement," International Journal of Heat and Mass Transfer, 44, pp. 2155-2161.

doi:10.1016/S0017-9310(00)00206-4

Tafti, D.K., 2005, "Evaluating the Role of Subgrid Stress Modeling in a Ribbed Duct for the Internal Cooling of Turbine Blades," International Journal of Heat and Fluid Flow, 26, pp. 92-104.

doi:10.1016/i.ijheatfluidflow.2004.07.002

Taslim, M.E., Li, T., and Kercher, D.M., 1996, "Experimental Heat Transfer and Friction in Channels Roughened with Angled, V-shaped, and Discrete ribs on Two Opposite Walls," Journal of Turbomachinery, 118, pp. 20-28. ISSN: 0889504X

Webb, R.L., Eckert, E.R.G., and Goldstain, R.J., 1971, "Heat Transfer and Friction in Tubes with Repeated Rib Roughness," International Journal of Heat and Mass Transfer, 15, pp. 1647-1658. doi:10.1016/0017-9310(71)90009-3

Webb, R.L., and Kim, N.H., 2005, Principles of Enhanced Heat Transfer, $2^{\text {nd }}$ ed., John Wiley\&Sons, New York. 